\title{
CONDOMÍNIOS EMPRESARIAIS EM ÁREAS METROPOLITANAS DO ESTADO DE SÃO PAULO: UMA NOVA ESTRATÉGIA IMOBILIÁRIA ${ }^{1}$
}

\author{
Rodolfo Finatti*
}

\section{RESUMO:}

Os condomínios empresariais podem ser apontados como um tipo de empreendimento recente no Brasil e no Estado de São Paulo. Em linhas gerais, começaram a instalar-se no final da década de 1990 e constituem novos espaços de uso produtivo. Expressam novas estratégias de atuação do capital imobiliário, associando tendências da reestruturação produtiva, como o imperativo da fluidez territorial, à urbanização e globalização em curso. O presente trabalho objetiva classificar estes empreendimentos a partir da análise de suas principais características infraestruturais e a intencionalidade que apresentam.

\section{PALAVRAS-CHAVE:}

condomínios empresariais, urbanização, globalização, circulação, reestruturação produtiva.

\begin{abstract}
:
The enterprises condominium are a kind of recent undertaking in Brazil and State of São Paulo. Generally speaking, they started in the end of the nineties decade and consists of new spaces for productive use. They express new manners of real estate capital, whose associates tendencies of productive, like the territorial flowing imperative, at urbanization and globalization in course. This work objective is to classify such undertakings, analyzing their main infra-structural characteristics and intentionality.
\end{abstract}

\section{KEYWORDS:}

enterprises condominium, urbanization, globalization, circulation, productive reestructuring.

\section{Introdução}

Este artigo aborda questões sobre os condomínios empresariais recentemente instalados nas áreas metropolitanas do Estado de São Paulo e também em áreas que poderíamos considerar como constituintes de uma macrometrópole estabelecida a partir da capital paulista. Tais empreendimentos podem ser traduzidos como uma ampliação das estratégias da produção imobiliária a partir da segunda metade da década de 1990, quando começam a ser implantados, uma vez que sua concepção se dá com uma intencionalidade bem definida de mercantilização do solo urbano.
Por conta desta mercantilização, os condomínios empresariais são produzidos e dotados de determinadas características, que primam por parâmetros como segurança, acessibilidade, diminuição de custos de operação, paisagismo, lazer e uma variada infraestrutura de serviços articulados aos empreendimentos, como restaurante, central de manutenção e serviços de limpeza. Entre estes parâmetros, há ainda uma grande ênfase para aqueles que garantiriam à empresa instalada os requisitos técnicos propícios à circulação rápida de informações, como as centrais telefônicas e os servidores de Internet. 
Estes últimos elementos, associados à forte proximidade que os condomínios empresariais apresentam em relação a eixos de circulação rodoviários, evidenciam a importância dada à fluidez territorial em sua concepção (oferecida para as unidades empresariais que se tornam clientes), revelando um pouco da intencionalidade dos incorporadores imobiliários em adequar seus produtos segundo os requerimentos contemporâneos da indústria e dos serviços.

Para esta apresentação inicial dos condomínios é preciso dizer que há variação na maneira como são configurados internamente, localizados e apresentados ao público: podem ter a partir de cinco mil ou mais de um milhão de metros quadrados; podem ser encontrados próximos à marginal do Rio Pinheiros ou em áreas urbanas distantes e descontínuas; próximos ao centro da metrópole ou em municípios de menor porte; podem, ainda, configurar-se em grandes lotes para instalações produtivas, em galpões modulares para operadores logísticos ou também em conjuntos de escritórios. Quanto às denominações empregadas, são também muito variadas: condomínios empresariais, condomínios industriais, condomínios de galpões, condomínios de escritórios, centros logísticos, parques industriais, business centers, business parks, etc.

É possível destacar, também, uma predominância horizontal do espaço construído e, evidentemente, o fechamento em relação ao exterior por meio de barreiras físicas e sistemas de segurança bastante reforçados. Essas características estão presentes em todos os condomínios que, até aqui, analisamos. Perante todos esses formatos e diferenças, entretanto, prevalece uma lógica que os marca conceitualmente: o condomínio voltado para empresas e promovido pela ação de agentes imobiliários.

Fica evidente o interesse na obtenção da renda do solo urbano, ganho que move as operações imobiliárias, cuja nova - ou ampliada - estratégia consiste em adequar seus produtos às diretrizes de outra clientela (diferente daquela associada aos condomínios residenciais), pouco explorada no oferecimento de produtos imobiliários. Esses agentes se aproveitam de uma demanda já existente ou mesmo tentam criá-la por meio de propagandas.

Portanto, é significativo que a aglomeração decorrente dos condomínios empresariais não se traduz em concentração de empresas similares capitaneada por uma empresa matriz e tampouco em distritos industriais conduzidos pelo poder público - modalidades predominantes em décadas anteriores -, mas sim a partir da ação de outros agentes econômicos, articulados ao capital imobiliário.

Em nossa investigação empírica, até o momento, foram encontrados por volta de 70 empreendimentos nas áreas metropolitanas de São Paulo e Campinas. Estes já estão implantados e com empresas instaladas, mas ressaltamos a previsão de mais condomínios, que atualmente estão em estágio de projeto. Neste ano de 2009, verificamos por meio de notícias veiculadas pela imprensa e canais de comunicação utilizados pelos agentes imobiliários, certa euforia relacionada ao crescimento desta natureza de empreendimentos, de maneira que se torna difícil sua quantificação exata e acompanhamento.

A partir dessa caracterização inicial, abordaremos três aspectos principais, que podem ser reveladores das estratégias imobiliárias consubstanciadas aos condomínios, mas também de outras problemáticas importantes a que estão relacionados: em primeiro lugar, vale uma tentativa de classificação para melhor compreendê-los, bem como sua distribuição no contexto das áreas metropolitanas, seguido por uma abordagem sobre a importância da proximidade com eixos de circulação e com certo dinamismo atribuído às metrópoles, elementos com os quais estabelecem forte relação. Posteriormente, são destacados os elementos infraestruturais que também podem auxiliar em sua compreensão e na maneira como se procura criar uma psicoesfera para demanda empresarial, acelerando a mercantilização destes empreendimentos. Por fim, destacamos como se articulam os processos de urbanização e globalização vistos a partir dos condomínios 
empresariais, comentando o papel dos agentes de produção imobiliária nesse contexto, o que remete ao processo contraditório de sua produção territorial.

\section{Classificação e distribuição dos empreendimentos na área de estudo}

Com base na observação das características dos condomínios empresariais encontrados nas áreas metropolitanas é possível proceder a uma classificação inicial e simples, que é baseada nos tipos de operações que os condomínios precedem, o que influi na sua produção física, na configuração de seu espaço interno e nas infraestruturas instaladas. Por essa razão, a classificação está relacionada ao oferecimento de localizações que almejam ser ideais segundo cada ramo da atividade produtiva, e daí surge a distinção entre os tipos de condomínios empresariais, bem como uma possível explicação para a distribuição que assumem na área de estudo.

Se retomarmos alguns pontos de teorias clássicas de localização, realizadas no campo da Economia Espacial, cujos expoentes foram J. H. von Thunen (no século XIX), A. Weber e W. Christaller (início do século XX), observamos que era comum o estabelecimento de modelos ideais, cujo objetivo era determinar uma localização ótima para as atividades agrícolas, industriais e também para os serviços. Já no escopo destas primeiras teorias, apesar do tratamento homogêneo dado ao espaço e do comportamento empresarial com uma racionalidade estritamente microeconômica, comum à escola neoclássica, é possível observar um destaque para os transportes e as características urbanas como variáveis importantes no processo de decisão locacional.

Para Weber, por exemplo, cuja teoria permite uma modelização para as atividades industriais, a localização considerada ótima se daria em função dos menores custos de transporte: o "método do triângulo", como ficou conhecido, funciona a partir das distâncias relativas entre as fontes de energia, matéria-prima e mercado consumidor, que deveriam ser consideradas de acordo com o tipo de indústria e os deslocamentos predominantes que seria preciso realizar, contabilizando os custos deste processo (MÉNDEZ, 1997). Nesta teoria, pioneira acerca da localização das indústrias, "o transporte é o fator primordial, já que, encontrando-se o ponto de custo mínimo, os outros fatores são encarados como desvios" (MANZAGOL, 1985, p. 26).

Na concepção de Christaller, por sua vez, as atividades econômicas estariam hierarquicamente distribuídas em redes urbanas em função de um lugar central, que "[...] aparece apenas porque determinadas funções da cidade vão ser efetuadas através de atividades que têm necessidade de ter uma localização central" (ABLAS, 1982, p.27), de maneira que, enfocando principalmente as atividades terciárias, propunha explicar sua localização por meio de um posicionamento hierárquico dos centros urbanos.

As decisões locacionais comparecem à problemática dos condomínios empresariais, em primeiro lugar porque são resultado de uma decisão desse tipo, mas principalmente por conta da localização de atividades produtivas em áreas previamente delimitadas pela ação de agentes imobiliários. É possível observar, por conta da recuperação destas noções clássicas da teoria de localização, que a própria localização dos condomínios remete a situações tradicionais em sua topologia com outros objetos geográficos, na medida em que são inseridos significativamente próximos a eixos de circulação e também a importantes centros urbanos. Dessa forma, os empreendimentos atenderiam a essas diretrizes já clássicas da localização das indústrias e dos serviços, mas esta explicação é insuficiente porque, ao mesmo tempo, esses empreendimentos se localizam em razão das alterações organizacionais que a esfera produtiva conhece a partir da década de 1970.

Como já destacava P. George, "a localização das indústrias obedece a imperativos e reage a solicitações cuja natureza e peso variam com as qualidades específicas das fabricações encaradas" (1967, p. 77), o que encontra reverberação na complexificação da atividade econômica a partir da passagem do paradigma 
produtivo assentado nas estratégias do fordismo para o paradigma produtivo flexível. Esse paradigma inicia-se a partir da crise na demanda pela qual passava o fordismo na década de 1970, e foi propiciado por reestruturações organizacionais e espaciais, sustentadas por inovações tecno-científicas (BENKO, 1996) inseridas em diferentes etapas da produção e nos circuitos de comunicação das empresas.

A inserção nessa lógica de acumulação flexível não é, evidentemente, um dado absoluto para a atividade produtiva e tampouco para todos os lugares, mas parece ser uma compreensão válida se realizamos uma análise para diferentes etapas segmentadas de um circuito maior, atualmente regido pelas exigências de uma economia mundializada. Os condomínios empresariais, segundo uma classificação possível e que tentaremos demonstrar, parecem estar articulados a alguns desses segmentos, bem como sua existência é também produto da adequação dos agentes imobiliários às nuances mais atuais resultantes da reestruturação produtiva.

Uma classificação possível para os condomínios empresariais procede destas adequações de produtos imobiliários, que se configuram distintamente dentro de uma lógica comum. A classificação é uma possível ferramenta para melhor compreendê-los, e está articulada à preparação concordante com o tipo de clientes que se deseje atingir ou, em outras palavras, com o tipo de empresa para o qual o empreendimento foi concebido. Por isso, complementarmente aos aspectos que são decorrentes da reestruturação produtiva, observamos que os empreendimentos são também organizados conforme a diferente vinculação ao circuito produtivo que as empresas estabelecem, de forma a ser oferecida uma localização "ideal" igualmente condizente.

Nessa lógica, os mais comuns e de maior número são os condomínios logísticos, que se valem do oferecimento de galpões modulares, principalmente para operadores logísticos; o segundo tipo com mais ocorrências são os condomínios de escritórios, que oferecem espaços menores, normalmente em conjunto de edifícios, com andares modulares para escritórios gerenciais e serviços; por fim, o tipo de condomínio empresarial mais complexo são os que chamamos de condomínios empresariais mistos, que misturam os tipos anteriores, uma vez que podem conter galpões de operadores logísticos, pequenos conjuntos de escritórios e também unidades de produção propriamente dita. Na tabela 1 expomos os tipos de condomínio empresarial definidos, o número encontrado em nossa área de pesquisa e também a superfície que ocupam.

Tabela 1.

Classificação dos con domínios, ocorrências e superfície ocupada 2009

\begin{tabular}{ccr} 
Classificação & Ocorrências & Superfície $\left(\mathrm{m}^{2}\right)$ \\
\hline Condomínios Logísticos & 45 & \\
Condomínios de Escritórios & 16 & 4.014 .599 \\
Condomínios Empresariais Mistos & 18 & 1.079 .498 \\
& &
\end{tabular}

Fonte: Pesquisa direta

Há condomínios primordialmente articulados para as etapas de armazenagem e distribuição das mercadorias que são, via de regra, condomínios de galpões modulares e, por atenderem às chamadas operações logísticas foram aqui denominados condomínios logísticos. Nestes, a prática do aluguel parece prevalecer e os galpões são facilmente adaptáveis, em seu 
tamanho e disposição, às operações de cada empresa. Constituem a maioria dos condomínios empresariais encontrados nas áreas metropolitanas de São Paulo e Campinas e apresentam-se em maior número porque sua estratégia pode estar vinculada, também, ao aproveitamento de antigas áreas ${ }^{2}$ de galpões que foram fechadas, melhoradas e transformadas em condomínios.

Os condomínios de escritórios são, geralmente, conjuntos de pequenos edifícios ( 3 ou 4 andares) com salas também facilmente moduláveis e que abrigam empresas de serviços e também de funções administrativas. É o tipo mais sofisticado no tocante ao oferecimento do paisagismo, áreas de lazer e distensão e também centros comerciais, terceirizados, em seu interior.

Os condomínios empresariais mistos, por sua vez, foram assim denominados porque possuem a maior diversidade das funções econômicas existentes: esses condomínios identificam-se porque seus incorporadores negociam as glebas internas, e não espaços já construídos e, dessa maneira, este tipo abriga desde unidades fabris propriamente ditas a centros de pesquisa e desenvolvimento, mas também operadores logísticos e escritórios ${ }^{3}$. Pela própria intencionalidade associada aos condomínios empresariais mistos e pela adequação que possuem ao setor produtivo, de maneira mais abrangente, são os que apresentam a maior extensão territorial total, apesar de estarem em número menor em relação aos logísticos.

A tabela 2 indica a predominância dos condomínios, segundo sua classificação, em função da localização: Região Metropolitana de São Paulo (RMSP), Região Metropolitana de Campinas (RMC) ou entorno metropolitano.

\section{Tabela 2.}

Classificação dos condomíni os segundo a local ização 2009

\begin{tabular}{cccc}
\hline Classificação & RMSP & RMC & Entorno metropolitano \\
\hline Condomínios Logísticos & 32 & 5 & 8 \\
Condomínios de Escritórios & 10 & 4 & 2 \\
Condomínios Empresariais Mistos & 5 & 7 & 6 \\
\hline
\end{tabular}

Fonte: Pesquisa direta

É bastante significativo que a Região Metropolitana de São Paulo concentre a grande maioria dos condomínios logísticos. Além de estarem inseridos no centro urbano que articula o principal nó rodoviário do estado, desfrutam de uma localização extremamente próxima ao centro corporativo que é sede das principais empresas do país. Apesar de ter bastante peso na atividade industrial e nos fluxos de exportação, isso se dá porque São Paulo é também uma metrópole informacional, como aponta M. Santos (1993). A informação é o principal insumo para as empresas que realizam operações logísticas, e a densidade de fluxos informacionais nestas empresas é grande, tendo em vista que realizam a centralização de pedidos e despachos, diariamente direcionados via telefone e Internet. Por isso, é importante os condomínios logísticos estarem próximos destes eixos de circulação material e imaterial que conhecem na capital o seu nó articulador.

Os condomínios de escritórios estão equilibrados entre as duas metrópoles, mas pouco comparecem no entorno. No município de São Paulo é bastante comum a produção de edifícios para venda e locação para escritórios corporativos, que passaram a aglomerar-se desde a década de 1980 junto à marginal do Rio Pinheiros e ao novo centro corporativo da cidade 
no quadrante sudoeste, também produzido por agentes imobiliários, conforme explica M. Fix (2007). A instalação das sedes empresariais, principalmente as mais poderosas, fora do município de São Paulo, é uma novidade e só recentemente atinge áreas do interior, segundo Lencioni (2003), que também ressalta que mesmo esses escritórios, quando fora da concentração paulistana, não fogem a um raio de aproximadamente $100 \mathrm{~km}$ a partir da metrópole.

Os condomínios de escritórios, portanto, são a ampliação de uma estratégia já efetuada pelos agentes imobiliários. O diferencial neste tipo de condomínio é a maior disponibilidade de espaço interno e infraestruturas que os distinguem dos edifícios corporativos, dada sua predominância horizontal. Neste sentido, competem também com a instalação de sedes empresariais fora da aglomeração mais densa da macrometrópole.

Em relação aos condomínios empresariais mistos, entretanto, a dispersão dos empreendimentos é equilibrada entre a Região Metropolitana de São Paulo, de Campinas e o que seria parte do entorno metropolitano, como menção à área que é centralizada por Jundiaí e também ao Vale do Paraíba. Isso pode ser explicado, entre outros fatores, porque os condomínios empresariais demandam mais espaço para sua incorporação imobiliária: normalmente possuem áreas mais extensas e são mais afastados dos centros urbanos, até mesmo em significativa descontinuidade de seu tecido. Por conta desta necessidade de maior extensão de terra, é ainda mais explicativo que sejam produzidos afastados do centro da Região Metropolitana de São Paulo.

\section{A importância da circulação e da metrópole}

Estabelecendo um discurso que remete às teorias clássicas da localização industrial, a instalação dos condomínios empresariais se apoia na oferta de uma localização "ótima" para as empresas e demonstram a adaptação da produção imobiliária às diretrizes determinadas pelo empresariado, visando garantir, entre outros fatores, os atrativos da circulação rápida e de longo alcance e as externalidades decorrentes de uma inserção metropolitana.

Para ilustrar esse oferecimento, selecionamos alguns aspectos qualitativos, reveladores das intencionalidades associadas aos incorporadores imobiliários dos empreendimentos, que podem ser observados por meio dos discursos em que apoiam suas propagandas, conforme o quadro 1 . Trata-se de criar uma psicosfera para atrair uma demanda empresarial. Nestes discursos, fica evidente, em primeiro lugar, a importância em divulgar sua localização, levando em conta principalmente os aspectos da fluidez territorial e da proximidade com importantes centros urbanos. Há também menor ocorrência de outros aspectos promocionais, os quais mostraremos posteriormente.

É justamente por meio dos elementos fixos que se realizam os fluxos (SANTOS, 1988), e o estabelecimento de fluidez territorial é exatamente um parâmetro indispensável para a atividade produtiva, quer estejamos falando na circulação de bens materiais ou nos referindo à circulação de informações. É também importante a ideia de que "hoje, vivemos um mundo da rapidez e da fluidez" (SANTOS, 2002, p. 83), mas cuja condição é, na verdade, um privilégio de poucos: "A fluidez potencial aparece no imaginário e na ideologia como se fosse um bem comum, uma fluidez para todos, quando, na verdade, apenas alguns agentes têm a possibilidade de utilizá-la, tornando-se, desse modo, os detentores efetivos da velocidade" (SANTOS, 2002,p. 83).

A fluidez territorial permitida pelos importantes eixos rodoviários em que se instalam, em termos materiais, e pelos objetos técnicos, fixos, que promovem a circulação de informações, em termos imateriais, é o indicativo de um potencial circulação de alcance internacional. Ao mesmo tempo as vantagens promovidas pela inserção metropolitana, principalmente em termos de mão-de-obra especializada e proximidade a centros de pesquisa e desenvolvimento, são trunfos igualmente ofertados por conta da localização que assumem. 


\section{Quadro 1.}

Elementos discursivos nas propagandas dos condomínios empresariais 2009

\begin{tabular}{|c|c|c|}
\hline Condomínio & Descrição & Fonte \\
\hline $\begin{array}{l}\text { E-Business } \\
\text { Park } \\
\text { (São Paulo) }\end{array}$ & $\begin{array}{c}\text { "Localizado no tradicional bairro da Lapa, zona oeste de São Paulo, } \\
\text { próximo à Ponte do Piqueri, seu acesso é bem fácil: pela Marginal Tietê e } \\
\text { a poucos minutos das saídas das rodovias An hanguera, Bandeirantes, } \\
\text { Castelo Branco, Via Dutra e Ayrton Senna" }\end{array}$ & $\begin{array}{c}\text { Institucional } \\
\text { (jul. 2009) }\end{array}$ \\
\hline $\begin{array}{l}\text { Panamerica } \\
\text { Park } \\
\text { (São Paulo) }\end{array}$ & $\begin{array}{c}\text { "O projeto compreende um complexo de nove edifícios - sete de } \\
\text { escritórios e dois high tech - cercado pelas princi pais multinacionais, } \\
\text { shopping centers, hotéis e tran sportes públicos. Além disso, o projeto } \\
\text { oferece um edifício com amenidades que inclui acad emia, restaurantes, } \\
\text { bancos e o escritório de gerenciamento predial" }\end{array}$ & $\begin{array}{c}\text { Institucional } \\
(a b r .2009)\end{array}$ \\
\hline $\begin{array}{l}\text { GreenValley } \\
\text { Office Park } \\
\text { (Barueri) }\end{array}$ & $\begin{array}{l}\text { "O complexo oferece a mais modern a tecnologia em telecomunicações e } \\
\text { informática, com Internet de alta velocidade, áudio e vídeo conferência e } \\
\text { um gestor de telecomunicações. Também prima pela segurança } 24 \text { horas, } \\
\text { com circuito interno de TV, portaria única com controle de acesso e ronda } \\
\text { motorizada [...] O empreendimento foi construído tendo em vista a } \\
\text { melhoria do acesso a Alphaville, seja por meio da Rodovia Castelo } \\
\text { Branco, seja pelo Rodoanel ou, ainda, por meio de um metrô de } \\
\text { superfície que liga Barueri ao Terminal Rodoviário da Barra Funda" }\end{array}$ & $\begin{array}{l}\text { Revista Viva São } \\
\text { Paulo } \\
\text { (nov. 2004) }\end{array}$ \\
\hline $\begin{array}{l}\text { Parque } \\
\text { Industrial San } \\
\text { Jose } \\
\text { (Cotia) }\end{array}$ & $\begin{array}{l}\text { "Esse loteamento foi concebido depois de um estudo complexo das } \\
\text { necessidades da maioria das empresas pequenas e médias procurando } \\
\text { um local para a sede. O loteamento tem a qualidade de primeiro mundo, } \\
\text { num local muito privilegiado, com toda infra-estrutura pronta [...] O } \\
\text { loteamento foi totalmente projetado para que tenha amplo espaço, área } \\
\text { verde, iluminação, limpeza e segurança. O empresário sentirá muito mais } \\
\text { realizado de trabalhar no local com muito espaço, do estilo que não mais } \\
\text { se encontra na cidade de São Paulo. Todos os lotes tem vista ótima e } \\
\text { além disso, foi projetado uma linda pista de cooper para o seus } \\
\text { funcionários que querem aliviar o stress de cada dia" }\end{array}$ & $\begin{array}{c}\text { Institucion al } \\
(\text { abr. 2009) }\end{array}$ \\
\hline $\begin{array}{l}\text { FazGran } \\
\text { (Jundiaí) }\end{array}$ & $\begin{array}{l}\text { "Sobressair no concorrido mercado globalizado de hoje, cada vez mais, } \\
\text { exige das empresas visão e bom-senso para instalar estrategicamente } \\
\text { suas unidad es administrativas e produtivas. Infra-estrutura adequada, } \\
\text { comunicação ágil, acesso fácil e logística eficiente, têm sido exigências } \\
\text { decisivas para o sucesso na escolha do melhor local" }\end{array}$ & $\begin{array}{l}\text { Institucional } \\
\text { (mai. 2009) }\end{array}$ \\
\hline $\begin{array}{l}\text { Swiss Park } \\
\text { Office } \\
\text { (Campinas) }\end{array}$ & $\begin{array}{c}\text { "A grande inovação trazida pelo Swiss Park Office [...] é a localização. } \\
\text { Não há nenhum outro emp reen dimento como esse na Rodovia } \\
\text { Anhanguera, que possibilita fácil acesso a São Paulo, ao Aeroporto de } \\
\text { Viracopos e a outros pontos estratégicos da cidade" }\end{array}$ & $\begin{array}{l}\text { Revista } \\
\text { Metrópole } \\
\text { (ago. 2008) }\end{array}$ \\
\hline $\begin{array}{c}\text { Praça Capital } \\
\text { (Campinas) }\end{array}$ & $\begin{array}{c}\text { "O projeto propicia convívio, interação entre os profissionais e está em } \\
\text { local de fácil acesso à Campinas e sua região metropolitana. O Praça é } \\
\text { um conceito inédito em Campinas, que veio para humanizar o mundo } \\
\text { corporativo" }\end{array}$ & $\begin{array}{l}\text { Revista } \\
\text { Metrópole } \\
\text { (ago. 2008) }\end{array}$ \\
\hline
\end{tabular}

Fonte: organização do autor

No âmbito de nossa área de estudo, a implantação dos condomínios está associada a dois aspectos; por um lado, a articulação com os eixos de circulação rodoviários é muito forte; e por outro e a situação geográfica dos condomínios está vinculada à proximidade dos centros urbanos 
mais dinâmicos da área metropolitana, se ampliadamente considerada: São Paulo, Campinas, Jundiaí e São José dos Campos.

Por isso, no tocante a esses aspectos e segundo o tratamento dado à questão por $M$. Santos (1994), essa condição pode ser expressiva do real objetivo locacional das empresas capitalistas, pois: "as localizações são cada vez mais comandadas, de um lado, pelas leis do Comércio Internacional e pela presença do Capital Geral necessário, por outro" (SANTOS, 1994, p.139). O processo de preparação do território, do qual os condomínios empresariais são exemplos, tende a privilegiar essas duas condições atreladas à sua localização, justamente porque: "[...] o que hoje realmente atribui maior possibilidade de lucro às empresas é a importância do seu acesso efetivo ao Capital Geral, que é, de um lado, a cidade como um todo e, de outro, as frações do território urbano preparadas para seu uso" (p. 138).

Outro aspecto também importante e relacionado ao imperativo da fluidez territorial que se associa aos condomínios empresariais é a própria circulação geral do capital, justificando sua localização e objetos técnicos e informacionais que Ihes são articulados. Já que o comércio internacional é um objetivo, as localizações desempenham o seu papel no tocante à competitividade que possibilitam. Muitas vezes esta competitividade é facilitada pelo território, de forma que se torna uma realidade ainda mais tangível "[...] reduzir o tempo e os custos da circulação de modo que o capital investido possa retornar mais rapidamente à esfera da produção e a acumulação possa se realizar com mais rapidez" (SMITH, 1988, p.142). Nesse sentido:

\footnotetext{
É por meio dessas linhas de menor resistência $e$, por consequência, de maior fluidez, que o mercado globalizado procura instalar a sua vocação de expansão [...] O chamado mercado global se impõe como razão principal da constituição desses espaços da fluidez e, logo, da sua utilização, impondo, por meio de tais lugares, um funcionamento que reproduz as suas próprias bases, a começar pela competitividade (SANTOS, 2002, p. 84).
}

Uma breve avaliação das rodovias nas quais os condomínios empresariais, majoritariamente, se inserem é reveladora desses objetivos: Anhanguera (SP-330), Bandeirantes (SP-348), Castello Branco (SP-280) e Dutra (BR-116). As rodovias estaduais deste grupo foram apontadas com posições de destaque no conjunto de todas as rodovias do país, segundo ranking recém divulgado pela Revista Quatro Rodas (ABCR, 2009): $1^{\circ}$ (Bandeirantes), $6^{\circ}$ (Castello Branco) e $8^{\circ}$ (Anhanguera).

Segundo pesquisa em curso, estas poderiam ser consideradas articuladas a eixos de desenvolvimento, conforme a concepção de E. S. Sposito (2007), em razão de um conjunto de elementos infraestruturais permissivos de fluxos materiais e imateriais, de proporcionarem condições mais favoráveis para a atividade industrial e também possíveis rebatimentos sociais articulados aos municípios dispostos nestes eixos.

A densidade técnica que os eixos de circulação promove, além da facilidade de conexão com escalas mais abrangentes, realiza também uma articulação mais direta com o meio técnico-científico-informacional (SANTOS, 2004) que tem sua mancha mais densa a partir do centro da Região Metropolitana de São Paulo (que é também o nó desses eixos rodoviários). A extensão do meio técnico-científico-informacional para o interior do Estado de São Paulo se dá justamente no sentido desses eixos, perpassando e ligando outras áreas importantes para a atividade produtiva, como o Rio de Janeiro pelo Vale do Paraíba e São Paulo, Jundiaí e Campinas pelo Sistema Anhanguera-Bandeirantes.

Em um contexto ainda mais amplo e não menos importante, essas rodovias permitem à atividade produtiva alcançar com maior facilidade os extremos da Região Concentrada ${ }^{4}$, formada pelas macrorregiões sudeste e sul, na qual existe: "[...] atividades ligadas à globalização que produzem novíssimas formas específicas do terciário superior, um quaternário e um quinquenário ligados à finança, à assistência técnica e política e à informação em suas diferentes modalidades" (SANTOS E SILVEIRA, 
2001, p.269), que guarda elementos de significativo interesse para a atividade produtiva, de modo geral.

Todavia, certa ponderação é também necessária: uma análise sobre as decisões locacionais de unidades industriais no contexto dessas rodovias e eixos de desenvolvimento teve como conclusão, segundo C. A. de Oliveira (2009), a impossibilidade de afirmar que apenas o eixo é definidor das decisões locacionais, mas sim atuante na condição de espaço que conjuga elementos importantes para essas decisões, principalmente para o sistema produtivo flexível, como logística favorável, proximidade com mãode-obra especializada nos municípios que os margeiam, serviços financeiros e até segurança por conta da produção dos condomínios empresariais.

Assim, mais uma vez destacamos essa forte associação com os eixos de circulação rodoviários mais importantes do Estado de São Paulo, que não são escolhidos aleatoriamente para esses produtos imobiliários, os quais de maneira enfática oferecem "localizações estratégicas". Sua instalação ao redor de importantes centros metropolitanos, no mesmo sentido, não é ocasional e busca associar os condomínios ao conjunto de externalidades de que estes centros dispõem.

Para tentar ilustrar o movimento de articulação com escalas ampliadas, nosso estudo sobre o condomínio empresarial Techno Park Campinas e as empresas que estavam instaladas neste empreendimento, aponta que os fluxos de mercadorias e de informações articulados ao condomínio ocorriam, expressivamente, em escala mundial, bem como a abrangência das empresas, em sua organização em rede, se dava em escala nacional em $32 \%$ dos casos e em escala internacional em $48 \%$ dos casos (FINATTI, 2008). Perpassar essas diferentes escalas pode ser considerada uma necessidade operacional para algumas empresas instaladas em condomínios empresariais e, então, a localização deve ser efetivada também em função dessas combinações escalares, que a fluidez territorial permite.

\section{Principais infraestruturas nos condomínios empresariais}

Outros aspectos foram também destacados em menor intensidade nas propagandas do quadro 1 , como a segurança, os centros comerciais e de serviços e também as infraestruturas de lazer. Por isso, destacamos os demais elementos que são incorporados aos condomínios, na tabela 3 . Esses elementos infraestruturais incorporados aos condomínios fazem parte de uma "estratégia de diferenciação do produto" que os incorporadores imobiliários utilizam, para assim poder concorrer com outros e disputar os clientes.

Acreditamos que esses demais elementos contribuem também para uma visão geral sobre os condomínios empresariais, de maneira que revelam a segurança, em primeiro lugar, como elemento central da divulgação dos empreendimentos, seguido por facilidades de serviços como restaurante, ambulatório e auditório e pelo conjunto de infraestruturas que facilitam as telecomunicações: centrais telefônicas próprias, servidores locais de Internet e também a instalação de fibra ótica já articulada às dependências.

Entre os aparatos de segurança, que são os mais enfáticos nos dados quantitativos, foram encontrados alguns bastante sofisticados, como câmeras térmicas, leitoras de íris e também scanner biométrico. Outras categorias de infraestrutura estão presentes em menor número, principalmente aquelas relacionadas a momentos de distensão e prática esportiva, como paisagismo, academia, pista de corrida, churrasqueira e quadras poliesportivas. Ressaltamos ainda algumas condições bastante específicas e peculiares no conjunto dos condomínios investigados, como a presença de centros de comércio, agência de correio, posto de gasolina e até creche. Visando articular-se também a outros meios de transporte, alguns empreendimentos já possuem heliponto e há inclusive a notícia de um condomínio que terá um pequeno aeroporto de cargas em sua área interna, no município de Praia Grande, segundo foi veiculado pelo Jornal Baixada Santista (2008). 
Tabela 3.

Principais elementos de infraestrutura nos condomínios empresariais 2009

\begin{tabular}{ccc}
\hline Elemento da infraestrutura & Ocorrências & $\%$ \\
\hline Segurança & 65 & 84 \\
Restaurante & 39 & 50 \\
Central telefônica & 29 & 37 \\
Paisagismo & 20 & 26 \\
Internet & 17 & 22 \\
Auditório & 15 & 19 \\
Ambulatório & 13 & 17 \\
Fibra ótica & 11 & 14 \\
Heliponto & 11 & 14 \\
Posto bancário & 10 & 13 \\
\hline
\end{tabular}

Fonte: Pesquisa Direta

Em linhas gerais, o que temos observado é a adequação dos condomínios empresariais ao oferecimento da melhor localização possível, mas também da mais completa infraestrutura, na visão das empresas que irão se instalar neles. Sobre estas novas diretrizes, o oferecimento de segurança talvez seja o melhor exemplo das que emergem com a reestruturação produtiva, pois diretamente se vincula a um discurso atual e crescente de violência urbana, em todo o mundo, como indica Y. Pedrazzini (2006), e que também incentiva a produção dos enclaves fortificados urbanos de vários tipos (condomínios fechados residenciais, shopping centers, edifício corporativos), segundo a concepção de Caldeira (2000), aos quais seria possível acrescentar os condomínios empresariais.

Portanto, de maneira mais completa, o que se verifica é a inserção em espaços urbanos com intensa fluidez, material e imaterial, um requerimento tradicional da atividade industrial acrescido de diretrizes modernas como a circulação de informações, e outras que permeiam uma psicoesfera corporativa. Assim se revela a intencionalidade dos incorporadores imobiliários que concebem, planejam e fisicamente produzem estes espaços. A implantação dos condomínios será, então, uma tentativa de adequar-se às diretrizes do empresariado, levando em conta o aproveitamento de uma densidade técnica préexistente no território ou até mesmo influindo sobre os recursos públicos para intervir a seu favor - fator esse que não deve ser desprezado.

Para ilustrar um pouco melhor a atuação dos incorporadores imobiliários desses condomínios, as figuras 1 e 2 dizem respeito à propaganda realizada pela Brazilian Business Parks, que atua principalmente em Atibaia. Os outdoors, que foram fotografados nas margens de eixos rodoviários, se apropriam dos incentivos fiscais concedidos pelas Prefeituras Municipais e também trabalham a ideia do "sucesso empresarial" relacionado a estes novos espaços produtivos.

A utilização do marketing e, em certa medida, a criação de uma demanda a partir desta psicoesfera corporativa denota o poder que possuem os agentes imobiliários. Neste caso, espera-se que o próprio empresariado tenda a ser seduzido pela propaganda. Na figura 2, é expressiva a representação de uma pessoa procurando algo. Ela se utiliza de um binóculo, talvez em razão da dificuldade em encontrar uma 
localização ideal. Valoriza-se assim a ideia de um espaço pronto, urbanizado, corporativo e cheio de facilidades operacionais que irão ampliar os lucros da empresa.

Figura 1. Propaganda na Rodovia Bandeirantes, sentido interior.

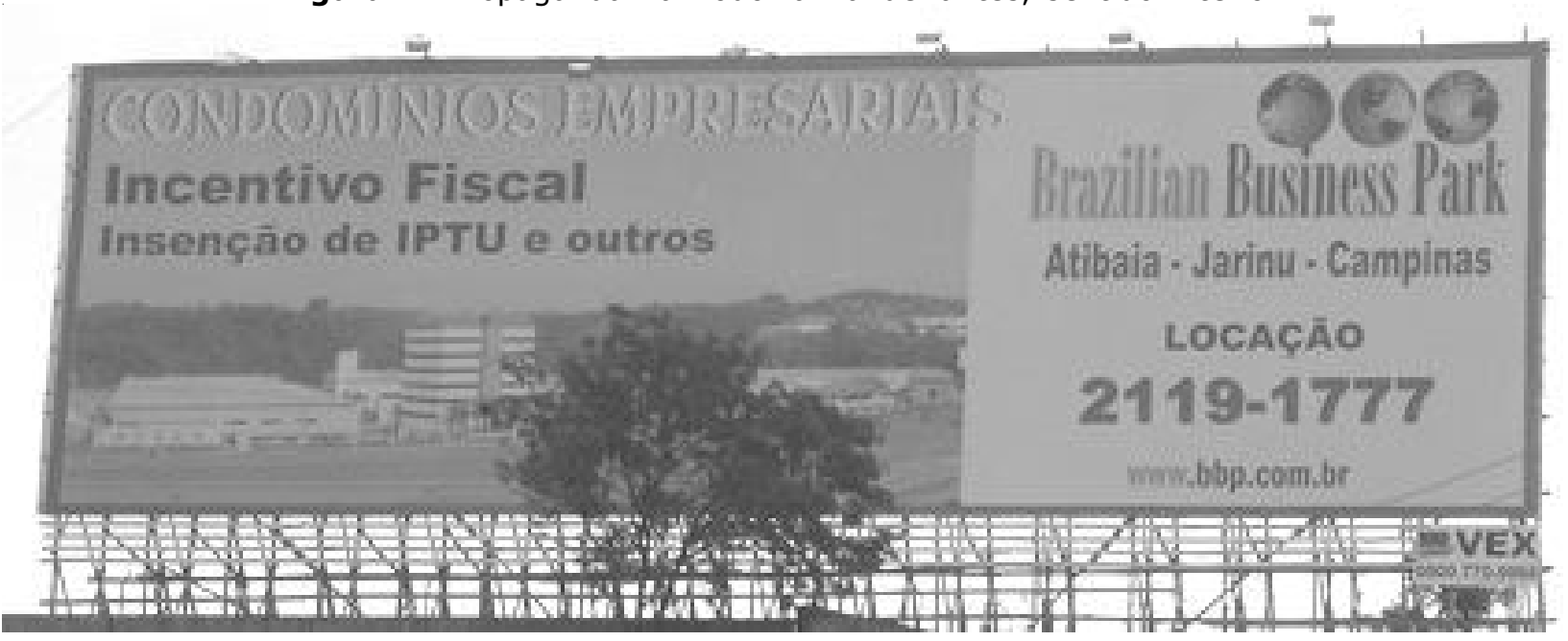

Fonte: Trabalho de campo, dez. 2008

Figura 2. Propaganda na Rodovia Dom Pedro I, sentido Atibaia.

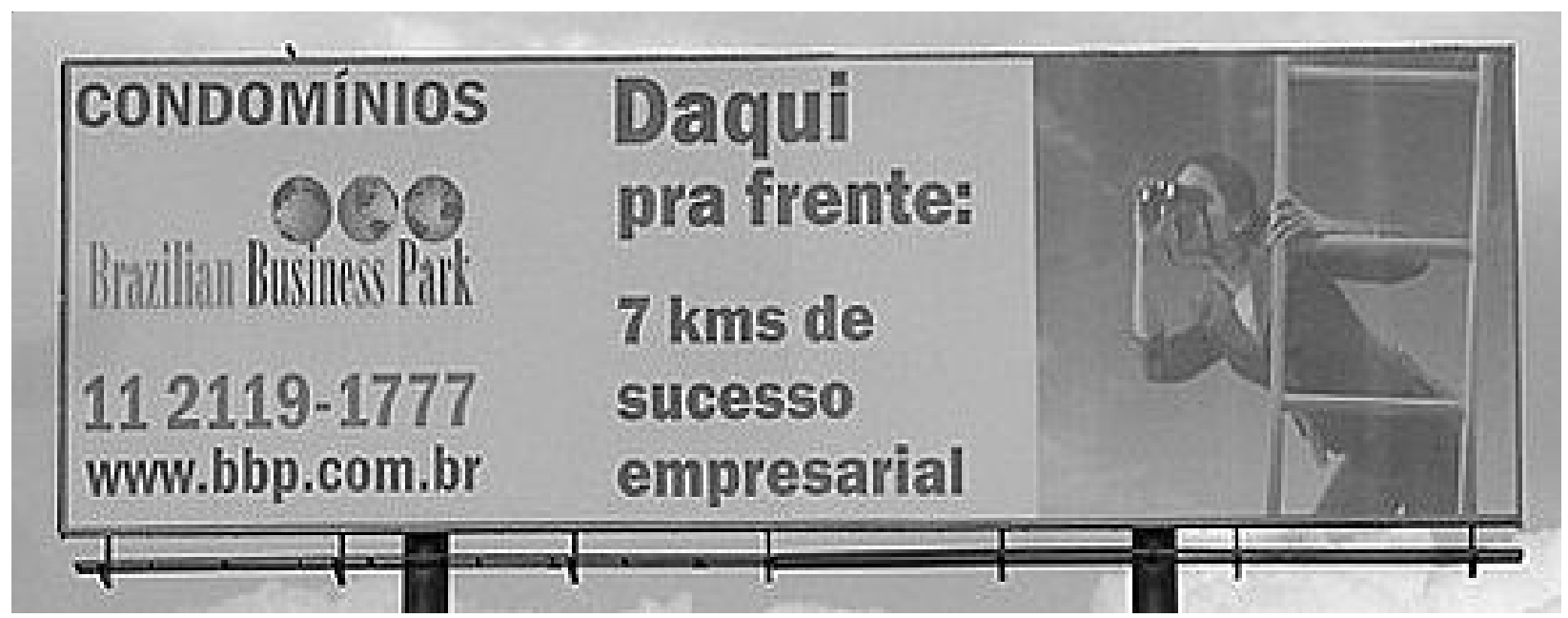

Fonte: Trabalho de campo, mai. 2009.

Mediante os fatores elencados pela retomada de alguns aspectos clássicos das teorias de localização, brevemente realizada no primeiro item deste texto, podemos destacar que há certa manutenção de fatores influentes e que tentam ser aproveitados pelos agentes imobiliários. 
Entretanto, há outros que mudam de significado mediante o processo de globalização em marcha e a própria constituição do território e sua produção corporativa, como se verifica com os condomínios empresariais.

Estamos em face do oferecimento de localizações, justificadas a partir da topologia que esses condomínios estabelecem com outros elementos espaciais, mas também da promoção de uma condição infraestrutural adequada às atividades empresariais modernas. Isso constitui uma novidade, pois sugere questões para se pensar até que ponto estas atividades estarão sujeitas à ação imobiliária, assim como estão, por vezes, as habitações e o grande comércio. O debate sobre a localização das atividades empresariais, ou industriais em seu sentido mais amplo, encontra na influência da produção imobiliária um elemento para sua complexificação.

\section{Urbanização, globalização e contexto de surgimento dos condomínios empresariais}

Os condomínios empresariais são produtos imobiliários, e o processo de urbanização está articulado, entre outros agentes, aos incorporadores imobiliários. Por isso, também nos preocupamos com esse processo, e a ação dos agentes imobiliários não pode ser desprezada, pois é relevante sua influência na definição das formas urbanas e de seus conteúdos.

Um ótimo exemplo, e igualmente vinculado ao setor corporativo, é o das Avenidas Berrini e Nações Unidas, em São Paulo. Analisadas por M. Fix (2007), formam uma paisagem reveladora do poder e do dinheiro das grandes corporações internacionais, mimetizando imponentes edifícios de arquitetura moderna, ora espelhados, ora chanfrados, para citarmos sua forma, e até mesmo "inteligentes", para falarmos das funções que desempenham no tocante às possibilidades comunicacionais, pois podem ser interpretados também como grandes objetos técnicos permissivos da produção e circulação de informações.
Os edifícios corporativos que resultaram das transformações na Berrini e Nações Unidas diferem substancialmente daqueles que fizeram da Avenida Paulista, em décadas anteriores, a sede do capital corporativo de São Paulo. Estes edifícios "[...] são em grande parte construídos como um investimento, para ser alugados" (FIX, 2007, p. 23), e promoveram a ideia de uma "nova cidade" que se desenvolvia seguindo o curso da marginal Pinheiros, então retificada, mas anteriormente uma área de várzea.

Dessa área, surge um novo centro em São Paulo, com função corporativa, sendo que: "a transformação de uma região pantanosa na área mais valorizada da cidade é, na verdade, um exemplo de criação da máquina imobiliária de crescimento" (p. 28). O exemplo utilizado por M. Fix para ilustrar essa máquina, mesmo em outro período, é o da Cia. City ${ }^{5}$, que influi sobre o poder público municipal, conseguindo promover uma legislação urbanística especial e que garantisse apenas investimentos urbanos destinados à alta renda, nas terras que possuía, visando sua valorização.

A "nova cidade" emerge a partir do final da década de 1970, transformando bairros residenciais e fabris no principal eixo de negócios de São Paulo e foram "[...] mais uma vez, produto da máquina imobiliária de crescimento. As novas articulações entre proprietários, promotores imobiliários e Estado foram responsáveis por um rápido processo de valorização imobiliária, apropriado pelos agentes privados" (FIX, 2007, p. 32).

As operações destes agentes são contraditórias, na condição de uma das feições da produção capitalista do espaço urbano. A disponibilidade de informação privilegiada usada para a especulação ou a influência sobre as decisões políticas que orientam a expansão do tecido urbano são estratégias da atuação dos agentes imobiliários. Os condomínios empresariais expressam, por seu turno, uma ampliação dos produtos dessa natureza de atividades, ou ainda uma nova estratégia, se nos apoiarmos na condição bastante recente desta 
natureza de produtos imobiliários, que objetiva conseguir a renda do solo urbano a partir da venda do título de propriedade ou aluguel, conforme explica P. Singer:

O uso do solo na economia capitalista é regulado pelo mecanismo de mercado, no qual se forma o preço desta mercadoria "suigeneris" que é o acesso à utilização do espaço. Este acesso pode ser ganho mediante a compra de um direito de propriedade ou mediante o pagamento de um aluguel periódico (1980, p. 78).

Dessa forma, nossa interpretação da urbanização está mais voltada para os papéis desempenhados pelos agentes privados ${ }^{6}$ envolvidos com a mercantilização do solo urbano, apesar de ser um processo mais amplo e, no caso dos condomínios, o poder público também estar associado ao processo. Em certa medida, nosso enfoque é mais diretamente o da produção territorial da cidade, muito embora os condomínios empresariais sejam não apenas forma, mas formas-conteúdo do período atual.

Em outra possível interpretação, os condomínios empresariais são expressão do meio técnico-científico-informacional, aquele no qual, segundo M. Santos (2004), "[...] a ciência e a tecnologia, junto com a informação, estão na própria base da produção, da utilização e do funcionamento do espaço" (p. 238). Assim, desde a extrema intencionalidade que os concebem até a funcionalidade dos objetos que estão articulados aos empreendimentos, altamente técnicos e também informacionais, passando pela fluidez territorial que promovem e a consequente possibilidade de atingir escalas ampliadas de comércio e comunicação, os condomínios empresariais são também espaços da globalização. Independentemente de atingirem ou não, efetivamente, essa escala de ação mundial, sua intencionalidade já é reveladora desta característica.

Uma vez que o meio técnico-científicoinformacional é a face geográfica da globalização (SANTOS, 2002), a urbanização promovida pelos incorporadores imobiliários, e que se articulada a este meio, da mesma forma, pode ser resposta ao contexto global ao pensarmos, por exemplo, na abertura econômica do Estado e internacionalização de capitais.

Os condomínios começam a surgir a partir da segunda metade da década de 1990, e pudemos também verificar que algumas incorporadoras imobiliárias por trás desses empreendimentos são de origem externa. Entre as que mais investiram no Brasil está a texana Hines, predominantemente na categoria de condomínios logísticos, mas que também esteve envolvida na implantação do Techno Park Campinas, um dos primeiros condomínios empresariais mistos do Brasil. A expansão desta empresa no segmento logístico-condominial está articulada à marca Distribution Park, que nomeia empreendimentos que, igualmente, funcionam como galpões modulares cujas dimensões são articuladas conforme a necessidade do operador. Além de condomínios que estarão presentes nas áreas metropolitanas do Estado de São Paulo (municípios de Louveira, Cajamar, Embu e Guarulhos), a expansão territorial destes empreendimentos seguiu para o Paraná (município de Araucária, na Região Metropolitana de Curitiba) e para o Amazonas (município de Manaus e também município central da Região Metropolitana).

Essa situação vem ao encontro de "[...] uma economia internacional, mais aberta e interdependente, e com uma crescente força política dos grandes grupos econômicos para definir o uso do território" (ARROYO, 2009, p. 483), o que leva a uma concentração e centralização do capital, que tende a privilegiar as metrópoles.

Para S. Lencioni (2008), além disso, a metrópole passa da condição de centro das políticas desenvolvimentistas à condição de sobrevida do capitalismo, contexto da globalização, cuja transição pode ser assim descrita: "Da cidade vista como pólo de desenvolvimento e da crença no planejamento urbano tecnocrático chegamos à cidade vista como um produto social inserida numa lógica da reprodução do capital, num contexto de refluxo da ação do Estado" (p.46-47). Na visão desta 
autora, os capitais definidores deste momento da metropolização são o imobiliário e o financeiro, e ocasionariam as transformações mais relevantes do espaço metropolitano, de maneira que:

\section{[...] é possível compreender porque o processo} de metropolização é acompanhado de renovação urbana. De um lado, porque a renovação se constitui numa estratégia central de competição entre as cidades por investimentos transnacionais e, por outro, porque se constitui numa estratégia da produção imobiliária internacional (LENCIONI, 2008, p. 50).

A financeirização da economia, da mesma forma, comparece na acentuação da mercantilização do desenvolvimento urbano, conforme indica C. A. de Mattos (2008). As estratégias imobiliárias que engendram a produção de condomínios para empresas sinalizam esta relação mais recente, bem como outras formas urbanas, como "[...] grandes proyectos urbanos (GPU), los edificios inteligentes y rascacielos para sedes de empresas transnacionales, los shopping-malls, los hoteles de cadenas multinacionales, etc., que como se verá tienen um impacto relevante em la organización y el funcionamento de las ciudades respectivas" (MATTOS, 2008, p. 29).

A possibilidade das empresas captarem recursos financeiros oferecendo suas ações na bolsa de valores, cuja ação por parte das incorporadoras imobiliárias é também recente, conforme indicam Quinto e Barros (2008), pode ter influência nesta variedade de produtos imobiliários e na euforia desses muitos condomínios empresariais lançados nos últimos anos.

É assim que, a partir da força do Estado que arrefece em alguns contextos, articulandose novas maneiras de atuação do capital financeiro e imobiliário, as formas de aglomeração industrial também se apresentam em um contexto diferenciado, podendo ser intermediadas pela produção imobiliária, para dar o exemplo de nosso estudo. Nas décadas anteriores, época da metrópole desenvolvimentista, foi com os desdobramentos dos Planos Nacionais de Desenvolvimento que se efetivaram alguns pólos tecnológicos no Estado de São Paulo, cujo planejamento apontava alguns municípios privilegiados entre os quais estavam São Paulo, Campinas e São José dos Campos, principais municípios que hoje albergam os condomínios empresariais. Nesse sentido, a atuação do capital imobiliário é indicativa também da estrutura econômica liberal vigente. A presença destes capitais no país não é específica da década de 1990, mas anterior. Os condomínios empresariais, contudo, apontam para essas alterações ainda mais peculiares do capitalismo recente.

Nesta marcha, quem fica de lado são as pessoas, a partir de "[...] nuevas formas de exclusión, segregación, fragmentación y tugurización, que han afectado negativamente la vida social de la mayoría de las grandes aglomeraciones urbanas" (MATTOS, 2006, p. 51), fenômeno este que está diretamente associado à nova morfologia urbana que se impõe, aos novos conteúdos centrais e periféricos por vezes determinados pela própria produção imobiliária, legitimada pelo Estado e seus critérios de seletividade nos gastos públicos.

Essa seletividade se dá em favor das grandes corporações e das classes média e alta, o que muitas vezes impõe aos pobres buscarem outros lugares para viver, sendo empurrados para ainda mais longe, como demonstra M. Santos (1990), ao abordar como a metrópole corporativa agrava a situação dos mais pobres, pois a distribuição de usos do solo e a localização anárquica das atividades e residências, associado à tendência de expansão a partir da prática da especulação imobiliária, os segrega ainda mais e também complexifica os seus deslocamentos diários dentro da aglomeração.

Neste contexto revelam-se contradições deste processo, no qual o principal do equipamento de infraestrutura, promovido pelo Estado, é feito em favor das empresas hegemônicas:

A ideologia do desenvolvimento, que tanto apreciamos nos anos 50, e sobretudo a 
ideologia do crescimento reinante desde fins dos anos 60 ajudam a criar o que podemos chamar de metrópole corporativa, muito mais preocupada com a eliminação das já mencionadas deseconomias urbanas do que com a produção de serviços sociais e com o bem-estar coletivo (SANTOS, 1990, p. 94).

Questionando-se também sobre as manifestações recentes do processo de urbanização, com enfoque no Estado de São Paulo, M. E. B. Sposito (2005) identifica uma difusão urbana do tipo reticular neste estado, que estaria associada, entre outros fatores, ao movimento de concentração e desconcentração econômica e espacial de atividades metropolitanas para o interior do estado nos últimos 30 anos. Nesse sentido, "quando essas duas dinâmicas - descontinuidade territorial e continuidade espacial - ocorrem simultaneamente e se articulam, pode se reconhecer, no plano da forma urbana, a constituição de rupturas no tecido urbano e, no plano das dinâmicas e processos, a realização da integração espacial" (SPOSITO, 2005 , p. 204). Com a ocorrência de rupturas, permitidas pelo meio técnico-científicoinformacional e sua difusão irregular, a cidade pode se apresentar fragmentada e territorialmente descontínua em relação à cidade precedente, marcada pela continuidade territorial.

O meio técnico-científico-informacional, cuja manifestação mais densa pode ser encontrada a partir da metrópole paulistana e seguidamente difundindo-se para o interior da Região Concentrada, pode ser associado à urbanização engendrada pelos incorporadores imobiliários e seus condomínios empresariais. A despeito de sua fragmentação em relação ao tecido urbano, se articulam ao meio geográfico pela circulação material e imaterial, uma vez que neste momento atual "A ação espacial não necessita da continuidade espacial [...] mas da continuidade temporal" (SANTOS, 1993, p. 101), que está garantida pelos objetos técnicos incorporados ao território, resultado, em grande parte, da ação destes agentes imobiliários, em função da adequação de seus produtos para a esfera empresarial, conforme já comentamos.
Assim, enquanto a maioria das pessoas sofre as consequências de uma produção territorial corporativa da cidade, as empresas a têm em seu favor. A cidade descontínua e fragmentada tem seus espaços apropriados seletivamente pelos agentes mais poderosos, capazes de se reservar os melhores pedaços do território. Quando associados aos empreendedores imobiliários e a influência que, por vezes, exercem sobre os vetores desta produção, ampliam-se suas possibilidades de localização e competitividade nas escalas intra e interurbana. Os condomínios empresariais, além disso, complexificam as possibilidades desta realização, pois reservam espaços e oferecem localização para uma variedade de unidades empresariais cujos representantes, até pouco tempo, desconheciam esses empreendimentos.

A urbanização e a globalização se imbricam no processo contraditório de produção desses condomínios empresariais. Tratam-se de territórios corporativos que participam de uma urbanização que, mais uma vez, privilegia os hegemônicos, tendo o território preparado em seu favor e para a operacionalização de seus interesses. O Estado, por sua vez, ao legitimar ou até apoiar esse tipo de implantação, negligencia a grande maioria das pessoas e suas reais necessidades.

\section{Considerações Finais}

A intencionalidade que direciona a produção dos condomínios empresariais demonstra uma ampliação dos usos corporativos do território por meio de uma nova estratégia imobiliária, que reverbera em nuances da própria dinâmica territorial da atividade das empresas.

Os condomínios empresariais, olhados a partir do capital que os engendra, o capital imobiliário, revela os interesses por trás de um processo contraditório de urbanização e globalização. A capacidade que esses agentes têm de influir nos vetores de expansão e condições infraestruturais da cidade, também em função dos condomínios empresariais, é uma questão a ser pensada e que deve estar associada à própria 
ação do Estado que, atualmente, também por meios políticos participa da "guerra de lugares" para atração de atividades econômicas.

Nesse sentido, além da complexificação da relação urbanização-industrialização, reside aqui uma atualização no debate sobre a localização das atividades produtivas no período contemporâneo, já que a localização e a aglomeração industrial, neste caso, passa a ser definida por outras estratégias e outros agentes. Estes, demasiadamente preocupados com a localização estratégica, com o fornecimento de infraestruturas cada vez mais adequadas e até mesmo com a criação de uma psicoesfera que divulgue seus produtos, estão recebendo cada vez mais unidades empresariais, bem como estão também lançando muitos empreendimentos desta natureza em tempo curto.

Diversas questões ficam abertas, mas principalmente aquelas sobre a ação das prefeituras municipais, no sentido de apoiarem a realização destes condomínios, a articulação destes empreendimentos com o capital em seu formato financeiro e também as várias implicações mais diretas e localizadas da descontinuidade e fragmentação urbana dos condomínios (relacionado também ao debate sobre as novas morfologias urbanas), devem ainda ser analisadas para aprofundar o conhecimento desta problemática.

\section{Notas}

${ }^{1}$ Este trabalho é componente de pesquisa de mestrado, em desenvolvimento no programa de pós-graduação em Geografia Humana da Universidade de São Paulo, sob orientação da Profa Dra María Mônica Arroyo, com auxílio da FAPESP e participante do projeto temático "Mapa da Indústria no Início do Século XXI. Diferentes Paradigmas para a Leitura Territorial da Dinâmica Econômica no Estado de São Paulo", coordenado pelo Prof. Dr. Eliseu Savério Sposito (Universidade Estadual Paulista, campus de Presidente Prudente).

${ }^{2}$ As operações da empresa Retha Imóveis \& Serviços, que se especializou nesta natureza de empreendimento, são indicativas de tais estratégias de adaptação de antigas áreas industriais.

${ }^{3} U m$ condomínio empresarial já estudado com mais profundidade, o Techno Park Campinas, apresentou $49 \%$ de operadores logísticos, 35\% de unidades de pesquisa e desenvolvimento e $16 \%$ de pequenas unidades fabris instaladas em seu espaço interno (FINATTI, 2008).

${ }^{4}$ Importa ressaltar que essas rodovias (e as que Ihes dão continuidade) têm uma mudança qualitativa muito grande ao sair do Estado de São Paulo, marcada por maior precariedade.

${ }^{5}$ Empresa que adquire $37 \%$ das terras em São Paulo em 1911, cujos diretores eram diretamente vinculados ao capital financeiro, às concessionárias dos serviços públicos e ao próprio Estado brasileiro. Esses incorporadores possuíam influência sobre o destino dos fundos públicos.

${ }^{6}$ Não apenas os incorporadores imobiliários, conforme há enfoque neste texto, mas também planejadores, construtores e comerciantes dos empreendimentos participam deste processo, conforme explica R. L. Corrêa (1995).

\section{Referências Bibliográficas}

ABLAS, L. A. de Q. A teoria do lugar central. Bases teóricas e evidências empíricas (estudo do caso de São Paulo). São Paulo, IPE-USP, 1982.

ANDRADE, M. C. de. Espaço, polarização e desenvolvimento (a teoria dos pólos de desenvolvimento e a realidade nordestina). São Paulo: Brasiliense, 1970 [1967].

ARROYO, M. A globalização pensada a partir do espaço geográfico. In: MENDONÇA, F., LOWERSAHR, C. L., SILVA, M. da. (orgs.). Espaço e 
Tempo: complexidades e desafios do pensar e do fazer geográfico. Curitiba: Ademadan, 2009. p.479-496.

ASSOCIAÇÃO BRASILEIRA DE CONCESSÕES DE RODOVIAS. Domínio virtual da instituição. Disponível em: <www.abcr.com.br $>$. Acesso em: jan. 2008.

BENKO, G. Economia, espaço e globalização na aurora do século XXI. São Paulo: Hucitec,1996.

CALDEIRA, T. P. do R. Cidade de muros: crime, segregação e cidadania em São Paulo. São Paulo: Editora 34/Edusp, 2000.

CORRÊA, R. L. O espaço urbano. São Paulo: Ática, 1995.

FINATTI, R. Reestruturação produtiva e produção do espaço urbano: a inserção interescalar do condomínio empresarial Techno Park Campinas, 2008. Monografia (Trabalho de Conclusão de Curso) - Faculdade de Ciências e Tecnologia, Universidade Estadual Paulista, Presidente Prudente.

FIX, M. São Paulo cidade global: fundamentos financeiros de uma miragem. São Paulo: Boitempo-ANPUR, 2007.

GEORGE, P. Geografia econômica. Rio de Janeiro/ Lisboa: Fundo de Cultura, 1967 [1958].

JORNAL BAIXADA SANTISTA. Praia Grande terá condomínio industrial com aeroporto de cargas. 27 de março de 2008. Disponível em: <praiagrande.jornalbaixadasantista.com.br/ conteudo/industrial condominio2008.asp>.

LENCIONI, S. Cisão territorial da indústria e integração regional do Estado de São Paulo. In: GONÇALVES, M. F., BRANDÃO, C. A., GALVÃO, A. C. (orgs.). Regiões e cidades, cidades nas regiões: o desafio urbano-regional. São Paulo: UNESPANPUR, 2003, p.465-475

- Da metrópole como estratégia desenvolvimentista à metrópole como sobrevida do capitalismo. In: PEREIRA, P. C. X. e HIDALGO, R. (orgs.). Producción inmobiliaria y reestructuración metropolitana en América Latina.
Santiago do Chile: Alfabeta Artes Gráficas, 2008. p.41-53.

MANZAGOL, C. Lógica do espaço industrial. São Paulo: Difel, 1985 [1980].

MATTOS, C. A. de. Globalización, negócios inmobiliarios y mercantilización del desarrollo urbano. In: PEREIRA, P. C. X. e HIDALGO, R. (orgs.). Producción inmobiliaria y reestructuración metropolitana en América Latina. Santiago do Chile: Alfabeta Artes Gráficas, 2008. p.23-40.

MATTOS, C. A. de. Modernización capitalista y transformación metropolitana em América Latina: cinco tendências constitutivas. In: LEMOS, A. I. G. de., ARROYO, M., SILVEIRA, M. L. América Latina: cidade, campo e turismo. (orgs.). Buenos Aires: Consejo Latinoamericano de Ciencias Sociales; São Paulo: Universidade de São Paulo, 2006. p.41-73.

MÉNDEZ, R. Geografia econômica: la lógica espacial del capitalismo global. Barcelona: Ariel, 1997.

OLIVEIRA, C. A. de. Influência dos eixos de desenvolvimento nas decisões de localização de empresas e análise das vantagens para a população após a concessão de parte da malha rodoviária do Estado de São Paulo. In: XI Simpósio Nacional de Geografia Urbana, 2009, Brasília. Vinte anos de reflexões sobre o urbano e a cidade: transformações e tendências. Brasília: Universidade Nacional de Brasília, Associação dos Geógrafos Brasileiros, 2009. CD-ROM.

PEDRAZZINI, Y. Violência nas cidades. São Paulo: Vozes, 2006.

QUINTO, L. de P. e BARROS, C. E. de. Impactos macroeconômicos do capital imobiliário do Brasil e suas repercussões em uma cidade de porte médio: Campos do Goitacazes. In: VIII Seminário Internacional da LARES, 2008, São Paulo. Mercados emergentes de real estate: novos desafios e oportunidades. São Paulo: Latin America Real Estate Society, 2008. CD-ROM.

RETHA IMÓVEIS E SERVIÇOS. Endereço eletrônico da empresa na Internet. Disponível em: <www.retha.com.br $>$. Acesso em: out. de 2009. 
SANTOS, M. Espaço e método. São Paulo: Nobel, 1985.

. Metamorfoses do espaço habitado. São Paulo: Hucitec, 1988.

Metrópole corporativa e fragmentada: o caso de São Paulo. São Paulo: Nobel, 1990.

. A urbanização brasileira. São Paulo: Hucitec, 1993.

- Por uma economia política da cidade: o caso de São Paulo. São Paulo: Hucitec, 1994.

. Por uma outra globalização. Rio de Janeiro: Record, 2002.

- A natureza do espaço: técnica e tempo, razão e emocão. São Paulo: Edusp, 2004 [1994].
SANTOS, M. e SILVEIRA, M. A. O Brasil: território e sociedade no início do século XXI. São Paulo: Record, 2001.

SINGER, P. O uso do solo urbano na economia capitalista. Boletim Paulista de Geografia. São Paulo, AGB, n.57, 1980, p.77-92.

SMITH, N. Desenvolvimento desigual. Rio de Janeiro: Bertrand Brasil, 1988 [1984].

SPOSITO, E. Reestruturação produtiva e reestruturação urbana no Estado de São Paulo. Scripta Nova. Revista electrónica de geografía y ciencias sociales, Universidad de Barcelona, vol. XI, núm. 245 (69), 01 de agosto de 2007. <www.ub.es/geocrit/sn/sn-24569.htm >.

SPOSITO, M. E. B. O chão em pedaços: urbanização, economia e cidades no Estado de São Paulo. 2005. Tese (Livre docência) Faculdade de Ciências e Tecnologia, Universidade Estadual Paulista, Presidente Prudente.

Trabalho enviado em outubro de 2009

Trabalho aceito em dezembro de 2009 